\title{
Comparison of Recurrence Rates in Patients with Locally Advanced Breast Cancer after Mastectomy and Received Aromatase Inhibitor Therapy with Steroids and Nonsteroids
}

\section{Ketut Yante ${ }^{1 *}$, Desak Gede Agung Suprabawati ${ }^{2}$, Iskandar $\mathbf{A l i}^{2}$}

${ }^{1}$ Fellowship student, Department of Surgery, Faculty of Medicine, Universitas Airlangga, Surabaya, Indonesia

${ }^{2}$ Department of Surgery, Faculty of Medicine, Universitas Airlangga, Surabaya, Indonesia

\section{A R T I C L E I N F O}

\section{Keywords:}

Breast cancer

aromatase inhibitor steroid

aromatase inhibitor non-steroid recurrence

\section{*Corresponding author:}

I Ketut Yante

\section{E-mail address: \\ nieketut@gmail.com}

All authors have reviewed and approved the final version of the manuscript.

https://doi.org/10.32539/bsm.v5i10.360

\begin{abstract}
A B S T R A C T
Background:. Breast cancer is a problem that is still faced throughout the world. The incidence of cancer in Indonesia is at number 8 in Southeast Asia. The incidence of breast cancer in women is 42.1 per 100,000 population. Aromatase inhibitors are hormonal therapy used in postmenopausal breast cancer with positive ER and/or positive PR. The third generation aromatase inhibitors are divided into 2 categories, namely non-steroidal agents that are reversible and steroid agents that are irreversible. Based on existing studies, there are no consistent research results regarding the incidence of recurrence after aromatase inhibitor therapy, both steroids and non-steroidal. Methods: This study is an analytical observational study with a retrospective cross-sectional design using secondary data from medical records. The research was carried out at the Surgical Clinic of RSUD dr. Soetomo Surabaya on October 1, 2020 until the end with the subject of LABC patients at POSA Surgery RSUD Dr. Soetomo who has undergone mastectomy and radiotherapy and has received adjuvant hormonal aromatase inhibitor therapy for 2 years from January 2018 to January 2020. Results: In the nonsteroidal aromatase inhibitor group, 18 subjects (60\%) experienced recurrence and 16 subjects in the steroid aromatase inhibitor group $(32 \%)$ with an OR of $0.314(0.12-0.81 ; p=0.014$. Based on the results of multivariate analysis, it was found that the increased risk of recurrence was significantly affected only by the administration of aromatase inhibitor $p=0.052$ Conclusion: Women with locally advanced breast cancer after mastectomy who received aromatase inhibitor steroid therapy had a 0.314 times lower risk of recurrence than those who received non-steroidal aromatase inhibitor therapy.
\end{abstract}

\section{Introduction}

The case of breast cancer is a problem that is still faced throughout the world. Globocan data states that in 2018 there were 18.1 million new cases with a death rate of 9.6 million deaths, where 1 in 5 men and 1 in 6 women in the world suffer from cancer. The data also states that 1 in 8 men and 1 in 11 women, dies of cancer. The incidence of cancer in Indonesia is at number 8 in Southeast Asia, while in Asia it is at 23. In women, breast cancer is the highest at 42.1 per 100,000 population with an average death rate of 17 per 100,000 population followed by cervical cancer. by 23.4 per 100,000 population with an average death rate of 13.9 per 100,000 population. ${ }^{1-6}$

Several research data conducted by several previous researchers still shows different results and there are no consistent research results regarding the incidence of recurrence after aromatase inhibitor therapy, ${ }^{3}$ both steroid and non-steroidal, researchers are interested in conducting further research related to the benefits of steroid and non-steroidal aromatase inhibitor therapy hormonal adjuvants in patients with locally advanced breast cancer who have undergone mastectomy to assess the incidence of recurrence $4,5,7$

\section{Methods}

This study was an analytical observational study with a retrospective cross-sectional design using secondary data from medical records. The research was conducted at POSA (One Roof Oncology Poly) Surgery RSUD dr. Soetomo Surabaya on October 1, 2020 until 
the end with the subject of LABC patients at POSA Surgery RSUD Dr. Soetomo who has undergone mastectomy and radiotherapy and has received adjuvant hormonal aromatase inhibitor therapy for 2 years from January 2018 to January 2020.

The inclusion criteria in this study were patients with locally advanced breast cancer (luminal type) who had menopause. Patients with locally advanced breast cancer (luminal type) who have undergone surgical mastectomy and radiotherapy were then continued with aromatase inhibitor therapy, both steroid and non-steroidal, for 2 years in the Surgical Oncology Division of the RSUD. Dr. Soetomo. The exclusion criteria used were LABC (luminal type) patients who had received aromatase inhibitor therapy but were replaced in the course of treatment with other types of hormonal therapy due to limited drug preparations in the pharmaceutical department.

\section{Results}

Based on the grouping of anatomical pathology results, it is divided into ductal carcinoma and nonductal carcinoma. The total subjects with anatomical pathology of ductal carcinoma were 59 subjects $(73.75 \%)$ and the results of anatomical pathology of non ductal carcinoma were 21 subjects $(26.25 \%)$.

Table 1. Characteristics of Research Subjects

\begin{tabular}{|c|c|c|c|c|c|c|}
\hline \multicolumn{2}{|c|}{ Characteristics } & & & \multirow[t]{2}{*}{ Total } & \multirow[t]{2}{*}{ P Value } & \multirow[t]{2}{*}{ OR } \\
\hline & & Yes & No & & & \\
\hline & Ductal & 21 & 38 & 59 & & \\
\hline Pathology & Carcinoma & $(35.6 \%)$ & $(64.4 \%)$ & (100\%) & 0.036 & 2.940 \\
\hline \multirow[t]{7}{*}{ Anatomy } & Non ductal & 13 & 8 & 21 & & \\
\hline & Carcinoma & $(61.9 \%)$ & $(38.1 \%)$ & $(100 \%)$ & & \\
\hline & Luminal A & 8 & 13 & 21 & & \\
\hline & & $(38.1 \%)$ & $(61,9 \%)$ & $(100 \%)$ & & \\
\hline & & & & & 0.634 & 1.280 \\
\hline & Luminal B & 26 & 33 & 59 & & \\
\hline & & $(44.1 \%)$ & $(55.9 \%)$ & $(100 \%)$ & & \\
\hline
\end{tabular}

In this study, the authors grouped research subjects based on the type of aromatase inhibitor therapy divided into non-steroidal aromatase inhibitors and steroids with recurrence events. Based on the results of data analysis, nonsteroidal aromatase inhibitors experienced recurrence in 18 subjects (60\%) while steroid aromatase inhibitors experienced 16 subjects (32\%). In the aromatase inhibitor group, 34 subjects (68\%) did not experience steroids, while the non-steroidal aromatase inhibitors were 12 subjects $(40 \%)$.

The author conducted a significance test with Chi
Square to see if there was a positive relationship between aromatase inhibitor therapy and recurrence. The results showed that there was a positive relationship between the type of aromatase inhibitor therapy and the incidence of recurrence in locally advanced breast cancer who had undergone mastectomy and received steroid and non-steroidal aromatase inhibitor therapy with a significance value of $0.014(\mathrm{P}$ value < 0.05) and the Mantel-Haenszel Common Odds test was performed. Ratio test with crude OR 0.314 results. Based on the grouping of anatomical pathology results, it is divided into ductal 
carcinoma and non-ductal carcinoma. The total subjects with anatomical pathology of ductal carcinoma were 59 subjects (73.75\%) and the results of anatomical pathology of non ductal carcinoma were 21 subjects $(26.25 \%)$.

Based on the luminal type, they were divided into two groups, namely Luminal A, Luminal B. In the luminal A group there were 21 subjects (26.26\%), while the luminal B group was 59 subjects (73.75\%). In the analysis based on age group, it was found that patients in the age group > 50 years tend to have a high recurrence rate with $\mathrm{p}$ value $=0.872(\mathrm{OR} 1.076)$. In the analysis based on the type of anatomical pathology, it was found that the subjects with the anatomical pathology of nonductal carcinoma tended to have a high recurrence rate with $\mathrm{p}$ value $=0.036$ (OR 2.940) . In the analysis based on luminal type, luminal B tends to have a high recurrence rate with $\mathrm{p}$ value $=0.634(\mathrm{OR}$ 1.280). Characteristics of research subjects can be seen in Table 1.

\section{Discussion}

The research subjects divided the anatomical pathology into two groups, namely ductal carcinoma and nonductal carcinoma. The ductal carcinoma group consisted of 59 subjects $(73.7 \%)$ while the nonductal carcinoma group consisted of 21 subjects (26.2\%). In this study, the lowest recurrence incidence was found in the anatomical pathology group of nonductal carcinoma as much as $61.9 \%$ compared to the anatomical pathology group of ductal carcinoma as much as $35.6 \%$. Data analysis showed that there was a significant difference based on the type of anatomic pathology and the recurrence rate of breast cancer $(\mathrm{p}=0.036)$.

The author conducted a test using the MantelHaenszel Common Odds ratio estimate test between the types of anatomical pathology results and the recurrence rate of breast cancer patients, the results obtained crude OR $=2,940$, which means that patients with anatomical pathology of nonductal carcinoma have a risk factor for recurrence of $2,940 x$ compared to the type of ductal carcinoma. . This is in accordance with the research conducted by Du, et al. 2018 which states that nonductal carcinoma is a type of anatomical pathology that has a higher recurrence rate than ductal carcinoma.

From the literature, the histopathological type of tumor is one of the prognoses that can be divided into 4 groups, very good, good, bad and very bad.8,9 Very good histopathological types were invasive cribriform, tubular, tubulelobular, and mucinous with 10-year survival of more than $80 \% .10,11$ The prognosis is good in mixed tubular histopathology, mixed tubular special type, atypical medullary and lobular alveolar with a 10year survival of $60-80 \% .10,11$ Papillary type is also included in the good prognosis, solid lobular, mixed ducatal and lobular.8 In particular, inflammatory breast cancer has a poor prognosis, namely invasive lobular and medullary. In most of the population, the most common type is invasive ductal carcinoma by $70 \% .12,13$

Research data on the use of aromatase inhibitor therapy are grouped into 2, namely steroidal and nonsteroidal aromatase inhibitors.14,15 From the results of this study, the subjects who used non-steroidal aromatase inhibitor therapy were 30 subjects $(37.5 \%)$ and 50 steroid aromatase inhibitors (62.5\%). In the group using non-steroidal aromatase inhibitors, 18 subjects $(60 \%)$ experienced recurrence, while in the group using aromatase inhibitor steroids, there were 16 subjects (32\%). While the non-steroidal aromatase inhibitor group that did not experience recurrence were 12 subjects (40\%) and the steroid aromatase inhibitor group were 34 subjects (68\%).

In this study, a correlation test was conducted or looked for the relationship of the variables. According to this research, the ratio of recurrence rates between steroid and non-steroidal aromatase inhibitors was $32 \%$ and $60 \%$. The data obtained reflected a statistically significant difference $(p=0.014)$ in the recurrence rate of breast cancer in locally advanced breast cancer patients after mastectomy who were given aromatase inhibitor therapy. 


\section{Conclusion}

Women with locally advanced breast cancer after matectomy who received aromatase inhibitor steroid therapy had a 0.314 times lower risk of recurrence than those who received non-steroidal aromatase inhibitor therapy.

\section{References}

1. Ahmad, A. (2013) 'Pathways to Breast Cancer Recurrence', ISRN Oncology, 2013, pp. 1-16. doi: $10.1155 / 2013 / 290568$.

2. Akbari, M. E. et al. (2016) 'Prognostic factors of recurrence (Early and late) and death in breast cancer patients in Iranian women', International Journal of Cancer Management, 9(6). doi: 10.17795/ijcp-5747.

3. Ali, A. et al. (2017) 'Aromatase Inhibitors for the adjuvant treatment of breast cancer in postmenopausal women', The Cochrane Database of Systematic Reviews. John Wiley \& Sons, Ltd, 2017(5), p. CD011133. doi: 10.1002/14651858.CD011133.pub2.

4. Augusto, T. V. et al. (2018) 'Acquired resistance to aromatase inhibitors: where we stand!, Endocrine-Related Cancer, 25(5), pp. R283R301. doi: 10.1530/ERC-17-0425.

5. Bradley, R. et al. (2015) 'Aromatase inhibitors versus tamoxifen in early breast cancer: Patient-level meta-analysis of the randomised trials', The Lancet, 386(10001), pp. 13411352. doi: 10.1016/S0140-6736(15)61074-1.

6. Bray, F. et al. (2018) 'Global cancer statistics 2018: GLOBOCAN estimates of incidence and mortality worldwide for 36 cancers in 185 countries', CA: A Cancer Journal for Clinicians, 68(6), pp. 394-424. doi: 10.3322/caac. 21492 .

7. Chu, E. and DeVita, V. T. (2019) Physicians' cancer chemotherapy drug manual 2018.

8. Costa, R., Hansen, N. and Gradishar, W. J. (2018) Locally advanced breast cancer. Fifth Edit, The Breast: Comprehensive Management of Benign and Malignant Diseases. Fifth Edit. Elsevier Inc. doi: 10.1016/B978-0-323-
35955-9.00063-5.

9. Du, T. et al. (2018) 'Invasive lobular and ductal breast carcinoma differ in immune response, protein translation efficiency and metabolism', Scientific Reports, 8(1), pp. 1-11. doi: $10.1038 / \mathrm{s} 41598-018-25357-0$

10. Garg, P. K. (2015) 'Response to: "Current definition of locally advanced breast cancer"', Current Oncology, 22(5), p. e411. doi: $10.3747 /$ co.22.2808.

11. Geisler, J. (2011) 'Differences between the nonsteroidal aromatase inhibitors anastrozole and letrozole- of clinical importance', British Journal of Cancer, 104(7), pp. 1059-1066. doi: 10.1038/bjc.2011.58.

12. Hornova, J. et al (2017) 'Locally advanced breast cancer in elderly patients' Biomed Pap Med Fac Univ Palacky Olomouc Czech Repub. 161(2): 217- 222

13. Li, Z. H. et al. (2016) 'Luminal B breast cancer: Patterns of recurrence and clinical outcome', Oncotarget, 7(40), pp. 65024-65033. doi: 10.18632/oncotarget. 11344.

14. Lonning, P. et al. (2003) 'Pharmacokinetics of third-generation aromatase inhibitors', Seminars in Oncology, 30(4 SUPPL. 14), pp. 23-32. doi: 10.1016/S0093-7754(03)00305-1.

15. Mohammed, S. A. et al. (2016) 'Role of aromatase and anastrozole in cancer treatment', International Journal of Pharmaceutical Sciences Review and Research, 40(1), pp. 135-140. 